\section{Improving together: a new quality framework for GP clusters in Scotland}

Smith et al's editorial is welcome in that it describes a way forward to promote quality in general practice in Scotland, but many GPs will be disappointed with it because of what it conspicuously fails to address. ${ }^{1}$

The authors ask GPs, among others, for 'patience', 'mutual trust, empathy, and lenience in judgement 'in the final paragraph. This is an extraordinarily audacious request on their part, given how long GPs have struggled to cope with the many negative consequences of the GP contract agreed by the BMA in 2004, and the sustained disinvestment imposed by the Scottish government since 2006. The combined impact of their policies contributed to the 'production' of the 'clinical environment', a euphemism for the inadequate and falling capacity, via the haemorrhaging of GPs and failure to attract new recruits.

GPs should be asking the BMA and the Scottish government to use this opportunity of a new contract for a complete overhaul of the way they are funded. A new system is required which ensures that the additional funding apportioned to deal with higher workload and unit costs is not at risk of being diverted away from patient services to personal incomes. They should also be asking the BMA to ensure the financial accountability of GPs, as opposed to the protectionist role that enables the variation in personal income, unrelated to performance.
For their union leaders to represent them legitimately in the future, GPs should demand transparency and access to the relevant documentation rather than the unacceptable secrecy and restricted access that characterises general practice funding to date. The latter may have been deemed essential by the BMA, but it self-evidently has not been in the interests of the majority of GPs, and, by virtue of their essential role, the interest of the NHS more widely.

Helene J Irvine,

Consultant in Public Health Medicine, NHS Greater Glasgow and Clyde.

E-mail: hirvineanhs.net

\section{REFERENCE}

1. Smith GI, Mercer SW, Gillies JCM, McDevitt A Improving together: a new quality framework for GP clusters in Scotland. Br J Gen Pract 2017; DOI: https://doi.org/10.3399/bjgp17X691601.

DOI: https://doi.org/10.3399/bjgp17X692297

\section{Helpful strategies for GPs seeing patients with MUPS}

I read with interest the article by the Norwegian research group.' I have only recently become aware of the diagnostic label MUPS, despite suffering from such symptoms for over 40 years.

In 1975 I was prescribed nitrazepam for myoclonic epilepsy, and suffered an adverse reaction to the drug that went unnoticed by doctors. I tried to commit suicide and was referred to psychiatry. I consumed antidepressants for 40 years. I discussed my symptoms ad nauseam with countless doctors for four decades. I cannot fault the amount of time that was spent with me at great cost to the NHS. I also suffered from IBS symptoms for 10 years. Exclusion diets and tablets made no difference. I then consulted a chiropractor who resolved my IBS problems in 6 weeks. My spine had been pressing on the nerves leading to the gut.

Six months later I was advised by my GP to stop taking nitrazepam. It very soon became clear that I do not suffer from depression and have not suffered from it for decades. My brain had been suppressed by the drug, resulting in many MUPS. I am now disabled physically and cognitively due to a horrendous withdrawal but am unable to achieve a diagnosis of protracted benzodiazepine withdrawal syndrome or other accurate description of my condition. Other diagnostic labels are preferred that do not implicate the drug. And so most of my adult life has been devastated by prescription drug side effects. My doctors adopted all the strategies suggested over the years. However, what would have helped me most would have been an understanding of the cause of my symptoms so that these could be properly addressed. Perhaps the questions should be 'Why is the label MUPS used at all?' and 'Why is it being discussed and promoted at this particular time?' And why have I been offered four referrals to psychiatry to discuss my current MUPS, which are neurological in nature and directly related to benzodiazepine withdrawal? I would be happy to hold a focus group with GPs that addressed these rather more probing and perhaps contentious questions.

Fiona $\mathrm{H}$ French,

Retired.

E-mail: fionahfrenchahotmail.com

\section{REFERENCE}

1. Aamland A, Fosse A, Ree E, et al. Helpful strategies for GPs seeing patients with medically unexplained physical symptoms: a focus group study. $\mathrm{Br} \mathrm{J}$ Gen Pract 2017; DOI: https://doi.org/10.3399/ bjgp17X691697. 